\title{
Study of Morphological Pattern of Anaemia at a Tertiary Care Centre
}

\author{
Rajni Choudhary ${ }^{1}$, Ashish Koshti², Reeni Malik ${ }^{3}$ \\ ${ }^{1}$ Department of Pathology, Gandhi Medical College, Bhopal, Madhya Pradesh, India. ${ }^{2}$ Department of \\ Pathology, Gandhi Medical College, Bhopal, Madhya Pradesh, India. ${ }^{3}$ Department of Pathology, Gandhi \\ Medical College, Bhopal, Madhya Pradesh, India.
}

\section{ABSTRACT}

\section{BACKGROUND}

Anaemia is a disease of low erythrocyte count and haemoglobin ( $\mathrm{Hb}$ ) concentration less than the normal range. The main causes of anaemia are a decrease in RBCs, their destruction and decrease of $\mathrm{Hb}$ synthesis. A useful method for diagnosis and classification of anaemias is based on the morphological appearance of RBCs on an ideal stained blood smear. The main terms used in such classification are normocytic normochromic, microcytic hypochromic and macrocytic anaemia. In general, microcytic hypochromic anaemias are caused by reduced haemoglobin synthesis (most commonly because of iron deficiency), while macrocytic anaemias caused by reduced DNA synthesis that impair the maturation of erythroid precursors in the bone marrow. Normocytic normochromic anaemias have diverse aetiologies; in some of these anaemias, specific abnormalities of red cell size and shape which is best appreciated through visual inspection of peripheral smears provide an important clue as to cause.

\section{METHODS}

Retrospectively and prospectively we evaluated the results of complete blood count (CBC) and peripheral blood picture (PBP) of all anaemic patients attending during the year 2018 (from 1st January to 31st December), in the Department of Pathology, Gandhi Medical College, Bhopal (M.P.).

\section{RESULTS}

Out of a total of 500 patients, 220 were males and 280 were females. Results of CBC and PBP showed that 145 (29\%), 275 (55\%) and $80(18 \%)$ of the patients had normocytic normochromic, microcytic hypochromic and macrocytic pattern of anaemia respectively.

\section{CONCLUSIONS}

The microcytic hypochromic pattern of anaemia is highly frequent among this sample of patients while the macrocytic pattern of anaemia is the lowest. According to gender groups, microcytic hypochromic pattern of anaemia is more common among females; malnutrition, increase of blood loss due to pregnancy or menstruation, and lack of iron absorption are the main causes, while the normocytic normochromic anaemia is highly prevalent among males, which is mainly due to blood loss or chronic diseases.

\section{KEY WORDS}

Anaemia, Haemoglobin, MCV, MCH, MCHC
Corresponding Author: Dr. Ashish Koshti, Department of Pathology, Gandhi Medical College, Bhopal, Madhya Pradesh, India. E-mail: drashishpath@gmail.com

DOI: $10.14260 / j e m d s / 2020 / 106$

Financial or Other Competing Interests: None.

How to Cite This Article:

Choudhary R, Koshti A, Malik R. Study of morphological pattern of anaemia at a tertiary care centre. J. Evolution Med. Dent. Sci.2020;9(08):468-472, 10.14260/jemds/2020/106

Submission 28-06-2019,

Peer Review 29-01-2020,

Acceptance 05-02-2020,

Published 24-02-2020.

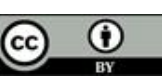




\section{BACKGROUND}

Anaemia is a medical condition in which the haemoglobin (Hb) concentration and erythrocyte count are lower than the normal range. The normal range of $\mathrm{Hb}$ and $\mathrm{RBCs}$ in general vary between males and females, it is defined as a $\mathrm{Hb}$ level of $<13.5 \mathrm{~g} / \mathrm{dL}$ and $<12.0 \mathrm{~g} / \mathrm{dL}$ in adult males and females respectively. The main causes of anaemia are a decrease in RBCs, insufficient $\mathrm{Hb}$ synthesis or increased RBCs destruction, and the primary cause is an iron deficiency.[1] Anaemia is the most common health issue in the world, and it affects a large population in almost all countries. The most frequent etiologies of anaemia are nutritional deficiencies, malaria, parasitic infections, blood loss, bone marrow replacement, or suppression and haemoglobinopathies. ${ }^{[2,3]}$

In India and other developing countries, nutritional anaemia most common clinical health problem. It is estimated that ranges from $33 \%$ to $89 \%$ among pregnant woman and is more than $60 \%$ in adolescent girls. National family health survey -3 (NFHS) ${ }^{[4]} 2005-06$, ministry of health and family welfare govt. of India conducted series of survey based on a sample of households that are representative at national and state level. Survey estimates the prevalence of anaemia 55.3\% among women of reproductive age (nonpregnant, non-lactating women) and $24 \%$ of men, $69.5 \%$ in children under 5 years of age. During reproductive life of female, menstrual blood loss, inadequate intake, helminthic infection, pregnancy, parturition and lactation significantly results in negative iron imbalance.[5,6,7] In India and other developing countries, prevalence of nutritional anaemia in reproductive age group ranges from $60-80 \%$ compared to 10 $20 \%$ in developed countries. ${ }^{[8]}$ Whatever the cause, moderate to severe anaemia leads to certain sign and symptoms. Patients appears to Pale, along with complaints of Weakness, malaise and easy fatigability. Lowered oxygenated blood in the body leads to dyspnoea on mild exertion. Hypoxia may lead fatty change in liver, myocardium and kidney.

On occasion, low oxygenated blood to myocardium leads angina, particularly when complicated by pre-existing coronary artery disease.[9] Iron in the form of haeme is essential to many metabolic functions including oxygen transportation in haemoglobin. Iron is also a component of various enzymes, including cytochromes, necessary for energy generation and drug metabolism.[10] It is the most prevalent nutritional deficiency worldwide.[11] Major causes of low iron include loss of blood, the maternal-fetal bridge, various parasitic infections, low dietary intake and malabsorption of iron.[12] Reports have also indicated that Helicobacter pylori can bind and extract iron from haemoglobin, transferrin, and lactoferrin.[13] Iron deficiency is defined as a decrease in total iron levels, along with low serum ferritin regardless of clinical expression. When the deficiency impairs erythropoiesis, it may result in a decrease in haemoglobin, with subsequent development of iron deficiency anaemia (IDA).

Normocytic hypochromic red cells have the central area of polar occupying about a third of the cell diameter and show reduced staining, with an increase in the central area of the pallor.[14] The morphological classification of anaemia is based on morphological criteria of red cells in ideal thin blood film, and also on red cells indices, mean corpuscular volume (MCV), mean cell haemoglobin $(\mathrm{MCH})$ and $\mathrm{MCH}$ concentration (MCHC).[15] This study is conducted to determine the most common morphological patterns of anaemia among the anaemic population, and this will give a good indication about the main cause of anaemia among such patients, besides formulating a good protocol for diagnosis. A blood smear is used to look for abnormalities in blood cells. The three main type of Blood cells are-

- Erythrocytes, which carry oxygen throughout the body.

- Leucocytes, which help to fight against infections and diseases.

- Thrombocytes, which are important for coagulation.

By the identification of size and shape of the cells help doctors diagnose certain blood disorders or other medical conditions. Irregularities in the number or shape of erythrocytes can affect travelling of $\mathrm{O}_{2}$ in the blood. These abnormalities are often initiated by deficiency of vitamins and minerals, but there are some hereditary conditions like sickle cell anaemia and thalassemia which also responsible for it. White blood cells are the important part of body's immune system, which is a network of tissues and cells that help body fight against infection. Either Leucopenia or Leucocytosis are the blood diseases. Disorders affecting leucocytes result in the body's inability to fight against infections or other inflammatory conditions. Abnormalities in the shape or number of Thrombocytes are signs of a platelet disorder. Platelet disorders affect coagulation of blood, which can lead to excessive or prolonged bleeding or clotting. They often occur when there is either thrombocytopenia or thrombocytosis. In a recent era, automated haematology analysers used for various haematology investigations for diagnosis of diseases, however microscopic evaluation of peripheral blood smears remain the gold standard to affords clinicians additional data that is helpful for diagnosis and treatment.

Examining the properly prepared and well stained peripheral blood smear allows to assess all blood cells morphology, parasites and other abnormalities that can by overlooked by haematology analyzers. With the help of peripheral smear examination, we can reach to the diagnosis of various disorders like anaemia, leukemias, infectious disease, inflammation, MPDs/MDS and bone marrow defects. In addition to morphology evaluation along with findings of haematology analyzer cellular counts and morphology of cells can be used to establish monitoring of progress throughout therapy. Many haematology cell counters do not provide a full information about RBC, WBC and platelets like absolute values of polymorphonuclear cell, band cells, lymphocytes, monocytes, eosinophils and basophils assist to differentiate between inflammation, microbial infection. For example, an increase in the count of band neutrophils is defined as a shift to the left. Giant platelets also not counted by analyzers. Additional evaluation parameters like identification of precursor cells, inclusions, parasites, cellular clumping and toxic granules, toxic vacuoles in leucocytes. Nucleated red blood cells in peripheral blood smear is indicative of bone marrow stress or damage. These nucleated RBC's by default counted in the total WBC count reported in haematology cell 
counter. Microscopic identification of these erythrocytes precursors allows for corrected WBC count. Inclusions within the cells found in both leukocytes and erythrocytes, Intracellular as well as Extracellular parasites may also be observe. Erroneous aggregation of platelets results in inaccurate counts when using automated cell counter.

Although blood cell counter may provide information regarding cell counts quickly, they have limitations. For morphological Evaluation peripheral blood smear examination is an important skill. The information reveals from blood smear examination combined with results of haematology analyzer help in the treatment of patients. The examination of Leishman stained blood smear frequently provides information regarding diagnosis of various blood cell disorders. Diameter of normal human red blood cells about $7.5 \mu \mathrm{m}$. They are anucleated and have central one third pallor due to inner portion of flexible biconcave disc being less thick than the outer portion. Their size is slightly smaller than small lymphocytes. The haemoglobin of red cells is located peripherally, leaving an area of central pallor equal to approximately 30 to $45 \%$ of the diameter of the cells. Cells of normal size and haemoglobin content are termed Normocytic and Normochromic. Erythrocytes Larger than small lymphocytes are termed as Macrocytes (diameter approximately greater than $9 \mu \mathrm{m}$ ) and red cells smaller than small lymphocytes termed Microcytes (diameter less than 6 $\mu \mathrm{m}$ ) and erythrocytes with central pallor greater than $50 \%$ of the diameter are hypochromic.

Variation of size of erythrocytes is termed Anisocytosis; and variation in shape is called Poikilocytosis. Significant increase in central pallor of erythrocytes is referred to as hypochromasia. Polychromatic RBCs means the red blood cells having blue-gray hue colouration of. For a diagnostic standpoint, recognition of Aniso- Poikilocytosis of red cells help to diagnose specific disorders. Spherocytes are the small rounded, deeply staining red cells that lack central pallor and have a smaller than normal RBCs. In Stomatocyte, central area is elliptical rather than round, giving the cell the appearance of the opening of a mouth (stoma). Target cells (codocytes) possess redistributed haemoglobin so that only the peripheral and the central regions of the cells appear haemoglobinised giving the cell the appearance of a target. Leptocytes having thin, peripheral rim of haemoglobin with central pallor. Sickle cells (drepanocytes) are elongated, slightly curved sometimes crescent-shaped, erythrocytes with pointed ends. Elliptocytes is characterized by red cells that are slightly oval to elongated cigar-shaped forms. The amount of haemoglobin is normal. Change in cholesterol distribution in the red cell membrane leads to accumulation of cholesterol in opposing polar ends results of elongation of red cells. Teardrop cell are red cells with one end rounded and the other end tapering. Acanthocytes have several (usually 3 to 7 ) irregular spicules having sharp ends. Echinocytes or burr cells possess uniform projections in size and are regularly spaced. Schistocytes are fragmented red blood cells appearing in a variety of morphologic forms such as small triangular erythrocytes, helmet cells, and normal-size erythrocytes with 2- to 3-pointed surface projections (keratocytes, or "horn cells"). Bite cells show contraction and bites on the membrane of red cells by the splenic macrophages. Rouleaux formation are the aggregates of red cells resembling stack of coin, generally in a curving pattern. Morphologic identification of inclusion bodies within the red blood cells are helpful. Howell-Jolly bodies are the inclusion of nuclear remnants (aggregates of chromatin material) presenting singly, or rarely multiply, seen in red cells. Basophilic stippling of red cells refers to numerous very small fine or coarse basophilic granules in the red blood cell. When the stippled particles are due to iron granules (demonstrable by the Prussian blue stain), they are termed Pappenheimer bodies. Malaria parasites also appear as cytoplasmic inclusion bodies within the red cells.

There are a number of important morphologic abnormalities of White blood cells. Cytoplasmic vacuolation may be seen. Toxic granulation refers to small, dark blue granules. Döhle bodies are light blue cytoplasmic inclusions, 1 to $2 \mu \mathrm{m}$ in diameter. The Pelger-Huët anomaly, characterized by lack of segmentation of nuclei mature with bilobed/band forms/dumb-bell shaped/smooth rounded small nuclei in more than $70 \%$ of neutrophils. Hyper segmented neutrophils are cells in which there are six to ten nuclear segments. Reactive lymphocytes are usually larger than small lymphocytes, having moderate to large amount of dark blue cytoplasm may also having cytoplasmic vacuolization, and contain irregular nuclei that may be bean shaped or monocytoid sometime eccentric in position. Most platelets in the peripheral blood have diameters between 1 and $3 \mu \mathrm{m}$. Platelets greater than $3 \mu \mathrm{m}$ in diameter are "large" giant platelet or megathrombocyte. In a normal person usually less than $5 \%$ of the platelets appear large. Examination of the peripheral blood smear should be considered, along with review of the results of peripheral blood counts and red blood cell indices, an essential component of the initial evaluation of all patients with hematologic disorders.

\section{METHODS}

A hospital based observational study was carried out at Department of Pathology, Gandhi Medical College from 1st January to 31st December 2018. 500 patients were evaluated for morphological pattern of anaemia based on red cell indices, peripheral smear, and leukocyte and platelet parameters. Anaemia was defined according to WHO criteria as haemoglobin concentration lower than $13 \mathrm{~g} / \mathrm{dL}$ in men and $12 \mathrm{~g} / \mathrm{dL}$ in women.[16] The study was approved by IEC and informed consent was obtained from patients. Elderly was defined as a person 60 years and above according to WHO criteria. Anaemia was further graded into Mild, Moderate and Severe according to WHO criteria [17] as under-

\begin{tabular}{|c|c|}
\hline Mild & $11-12.9 \mathrm{~g} / \mathrm{dL}$ (Men) $11-11.9 \mathrm{~g} / \mathrm{dL}$ (women) \\
\hline Moderate & $8-10.9 \mathrm{~g} / \mathrm{dL}$ \\
\hline Severe & $<8 \mathrm{~g} / \mathrm{dL}$ \\
\hline \multicolumn{2}{|c|}{ Hb Concentration } \\
\hline
\end{tabular}

Microcytic anaemia was defined as MCV below $80 \mathrm{fl}$, normocytic as MCV between 80 and $100 \mathrm{fl}$ and macrocytic anaemia by an MCV above $100 \mathrm{fl.}$.[18] Dimorphic anaemia was defined with a normal MCV but a raised RDW (normal - 1115\%). All were correlated with Peripheral smear examination. 


\section{Inclusion Criteria}

Patients fulfilling the WHO criteria of anaemia haemoglobin of less than $13 \mathrm{gm} / \mathrm{dL}$ in males and less than $12 \mathrm{gm} / \mathrm{dL}$ in females.

\section{Exclusion Criteria}

Patient who's Hb is less than $13 \mathrm{gm} \%$ but has received blood transfusion in the last 3 months. Patients on treatment with iron, folic acid, B12 supplements.

\section{Statistical Analysis}

The data was collected and analysed using standard statistical chi - square test, $\mathrm{p}<0.05$ statistically significant. Data was entered in Microsoft excel and analysis was done using SPSS version 22 .

\section{RESULTS}

The results of CBC and PBP showed that 145 (29\%), 275 (55\%), and $80(16 \%)$ of the patients had normocytic normochromic, microcytic hypochromic and macrocytic pattern of anaemia respectively [Table 1]. The gender wise classification of the patterns revealed that 88 male patients and 57 female patients had normocytic normochromic patterns, while 210 female patients and 65 male patients had microcytic hypochromic patterns whereas 45 males patients and 35 case of female patients showed macrocytic pattern [Table 2].

Other significant findings seen in this study among patients of anaemia are: pancytopenia $60(12 \%)$, neutrophilia 50 (10\%), PMN toxic granules 15 (03\%), eosinophilia 05 (01\%), lymphocytosis 50 (10\%), and immature cells 15 (03\%). Patients having pancytopenia and immature cells further advised for bone marrow examination to rule out and diagnosis of aleukemic leukemia, subleukaemic leukemia, leukemia and other causes of anaemia. 15 (03\%) cases of anaemia in this study had already diagnosed leukemia.

\begin{tabular}{|c|c|}
\hline Morphological Patterns of Anaemia & Frequency (\%) \\
\hline Normocytic normochromic & $145(29 \%)$ \\
\hline Microcytic hypochromic & $275(55 \%)$ \\
\hline Macrocytic anaemia & $80(16 \%)$ \\
\hline Total & $\mathbf{5 0 0}$ \\
\hline $\begin{array}{c}\text { Table 1. Frequency of Morphological Patterns of Anaemia } \\
\text { among Study Participants }\end{array}$ \\
\hline
\end{tabular}

\begin{tabular}{|c|c|c|c|}
\hline Morphological Patterns of Anaemia & Males & Females & Total \\
\hline Normocytic normochromic & 88 & 57 & 145 \\
\hline Microcytic hypochromic & 65 & 210 & 275 \\
\hline Macrocytic anaemia & 45 & 35 & 80 \\
\hline Total & $\mathbf{1 9 8}$ & $\mathbf{3 0 2}$ & $\mathbf{5 0 0}$ \\
\hline $\begin{array}{c}\text { Table 2. Frequency of Morphological Patterns } \\
\text { among Study Participants with regard to Gender Groups }\end{array}$ \\
\hline
\end{tabular}

\begin{tabular}{|c|c|}
\hline Pancytopenia & $60(12 \%)$ \\
\hline Neutrophilia & $50(10 \%)$ \\
\hline Lymphocytosis & $50(10 \%)$ \\
\hline PMN Toxic granules & $15(03 \%)$ \\
\hline Immature cells & $15(03 \%)$ \\
\hline Eosinophilia & $05(01 \%)$ \\
\hline
\end{tabular}

\section{DISCUSSION}

The most common morphological type of anaemia was microcytic hypochromic anaemia (275) [55\%]), which was in accordance with Joshi et al.[19] (55.53\%) and Ahmed et al.[20] (56.6\%). In a study done by M. Bukar et al [21] 2009, Microcytic hypochromic anaemia was the commonest pattern with $64.9 \%$ followed by Dimorphic anaemia with $34.7 \%$ and Macrocytic anaemia with $0.4 \%$.

Our study showed that the Microcytic hypochromic pattern of anaemia was more frequent than the macrocytic pattern. The gender wise classification of the patterns revealed a microcytic hypochromic pattern of anaemia was more common among females. Malnutrition, an increase of blood loss due to pregnancy or menstruation, and lack of iron absorption are the main causes. In male patients, the frequency of the normocytic normochromic pattern of anaemia was high, which may be mainly due to blood loss or chronic diseases.[22] In normocytic anaemia, the important issue is to identify the main cause and to prescribe the right treatment. The aetiologies of normocytic normochromic anaemia are nutritional, renal diseases (e.g., renal failure) and increased red cell destruction. ${ }^{[22]}$ In macrocytic anaemia, the main causes are a low level of Vitamin B12 and a low level of erythrocyte folate. The estimation of both patterns of anaemia will guide the proper diagnosis of macrocytic anaemia.

The most common cause of folate deficiency is either nutritional or malabsorption of this vitamin. In contrast, the deficiency of Vitamin B12 is almost resulting from malabsorption. ${ }^{[23,24]}$

\section{CONCLUSIONS}

Iron deficiency anaemia is the most common type of anaemia seen mainly in women in the reproductive age group. In our study, adolescent women were found to have high prevalence of anaemia. Since anaemia is more prevalent among low socio-economic groups, higher diagnostic tests lead to financial burden to the patients. The study of basic blood parameters and peripheral smear examination are less expensive and mandatory in the work up of anaemia. Morphological patterns of anaemia reflect the underlying aetiology, the study of which would ensure benefits in the early detection and appropriate treatment. Iron deficiency anaemia being a nutritional anaemia, can be prevented by improving nutritional status, creating awareness, and educating people.

\section{REFERENCES}

[1] Veng-Pedersen P, Chapel S, Schmidt RL, et al. An integrated pharmacodynamic analysis of erythropoietin, 
reticulocyte and haemoglobin responses in acute anaemia. Pharm Res 2002;19 (11):1630-5.

[2] Gruchy GC. Clinical haematology in medical practice. In: Penington D, Rush B, Castaldi P, eds. Delhi, India: CBS Publisher, Taj Press 1987.

[3] Hoffbrand AV. Erythropoiesis and general aspects of anaemia. In: Hoffbrand AV, Pettit JE, eds. Essential Haematology. $3^{\text {rd }}$ edn. Oxford: Blackwell Scientific 1993: p. 12-35.

[4] International Institute for Population Sciences (IIPS) and Macro International. 2007. National Family Health Survey (NFHS-3), 2005-06: India: Volume II. Mumbai: IIPS.

[5] Mehta BC, Jhaveri K, Patel JC. Anaemia in pregnancy. A study of 210 cases. Indian J Med Sci 1971;25 (5):301-7.

[6] Henderson PA, Hillman RS. Characteristics of iron utilization in man. Blood 1969;34 (3):357-75.

[7] Hibbard BM, Hibbard EE. Folate metabolism and pregnancy. Brit Med Bull 1968;24:10.

[8] DC Dutta. Textbook of Obstetrics. $6^{\text {th }}$ edn. Central Book Agency Pvt. Ltd., 2009.

[9] Kumar V, Abbas AK, Fausto N. Robbins \& Contran Pathologic basis of disease. $8^{\text {th }}$ edn. Saunders Publication 2009.

[10] Naigamwalla DZ, Webb JA, Giger U. Iron deficiency anaemia. Can Vet J 2012;53 (3):250-6.

[11] Sierra LM, Calderon SS, Gomez J, et al. Prevalence of anaemia and evaluation of transferrin receptor (sTfR) in the diagnosis of iron deficiency in the hospitalized elderly patients: anaemia clinical studies in Chile. Article ID 646201, Anaemia 2012;2012:1-6.

[12] Kotze MJ, van Velden DP, van Rensburg SJ, et al. Pathogenic mechanisms underlying iron deficiency and iron overload: new insights for clinical application. EJIFCC 2009;20 (2):108-23.

[13] Miller JL. Iron deficiency anaemia: a common and curable disease. Cold Spring Harb Perspect Med 2013;3 (7):a011866.
[14] Hoggbrand AV, Catorsky $\quad$ D, Tuddenham EG. Postgraduate haematology. $5^{\text {th }}$ edn. Oxford: Blackwell 2005.

[15] Lafuente BJA, Fernández-Burriel TM, Almenara JLS, et al. Anaemia and functional incapacity at admission to a geriatric home. An Med Interna 2001;18 (1):9-12.

[16] Khusun H, Yip R, Schultink W, et al. World Health Organization haemoglobin cut-off points for the detection of anaemia are valid for an Indonesian population. Journal of Nutrition 1999;129 (9):1669-74.

[17] Benoist BD, McLean E, Egil I, et al. Worldwide prevalence of anaemia 1993-2005: WHO global database on anaemia. Spain: WHO, 2008.

[18] Van Hove L, Schisano T, Brace L. Anaemia diagnosis, classification and monitoring using Cell-Dyn technology reviewed for the new millennium. Laboratory haematology 2000;6:93-108.

[19] Joshi P, Joseph D, Bajpai P, et al. Prevalence of anaemia among the general population of Malwa (M.P.), India. J Evolution Med Dental Sci 2013;2 (1):46-51.

[20] Ahmed SG, Kagu MB. Morphological classification of anaemia among first-time blood donors in Northwest Nigeria and the implication of empirical haematinics therapy. Int J Biomed Health Sci 2011;7 (2):125-6.

[21] Bucker M, Audu BM, Sadauki HM, et al. Prevalence of Iron deficiency and megaloblstic anaemia at booking in a secondary health facility in North Eastern Nigeria. Niger Med J 2009;50 (2):33-7.

[22] Tefferi A. Anaemia in adults: a contemporary approach to diagnosis. Mayo Clin Proc 2003;78 (10):1274-80.

[23] Colon-Otero G, Menke D, Hook CC. A practical approach to the differential diagnosis and evaluation of the adult patient with macrocytic anaemia. Med Clin North Am 1992;76 (3):581-97.

[24] Hernández NL, Hernández GMT, Pintado CT, et al. Medicina Interna. C Rozman (Dir). 15 th edn. Madrid: Elsevier 2004: p. 1644-69. 